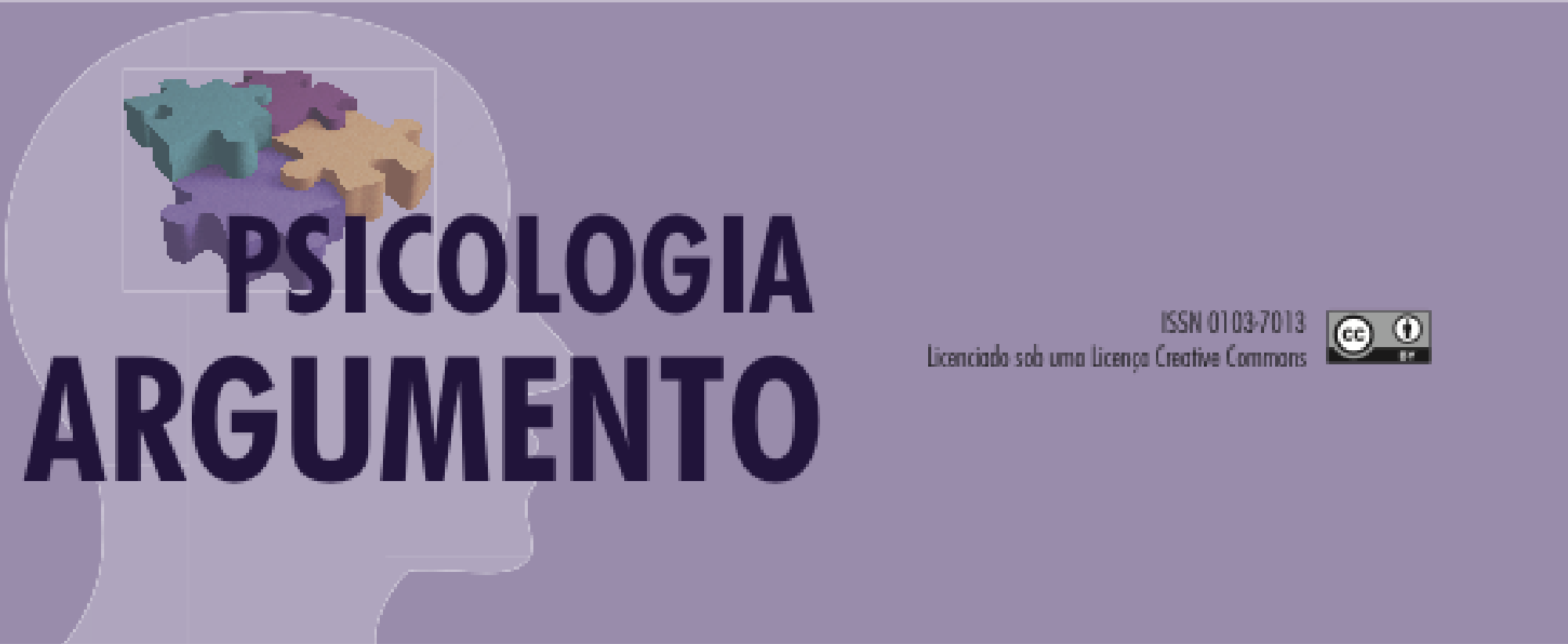

doi: http://dx.doi.org/10.7213/psicolargum.37.97.A004

\title{
Estudos longitudinais sobre desenvolvimento moral de adolescentes: uma revisão sistemática
}

Longitudinal studies about adolescents' moral development: a systematic review
Estudios longitudinales sobre el desarrollo moral del adolescente: una revisión sistemática.

\section{Eloá Losano de Abreu}

Universidade Federal da Paraíba, eloalosano@gmail.com ORCID: http://orcid.org/0000-0001-7712-6275

\section{Thalita Lays Fernandes de Alencar}

Universidade Federal da Paraíba, thalitaalays@hotmail.com

ORCID: https://orcid.org/0000-0003-3898-6242

\section{Resumo}

O objetivo deste estudo foi realizar uma revisão sistemática da literatura para verificar como o método longitudinal tem sido aplicado em estudos sobre o desenvolvimento moral de adolescentes. Foram realizadas buscas nas bases de dados PsycINFO e Periódicos Capes, utilizando termos como moralidade, adolescente e desenvolvimento moral. Foram identificados 6.229 artigos, dos quais 13 foram selecionados considerando critérios de inclusão e exclusão. Todos os artigos foram publicados entre os anos de 2008 e 2015. Os estudos apresentaram perspectivas teóricas diversas, abordando temas como formação da identidade, socialização, empatia, comprometimento religioso, e o julgamento moral. Ainda, identificou-se que os estudos analisaram um grande número de variáveis operacionalizadas. Observou-se que os estudos 
tiveram duração curta, utilizando de duas a três medidas, com pequeno intervalo de tempo entre elas. Todos os estudos efetuaram análises estatísticas avançadas. Concluiu-se que existe a necessidade de aperfeiçoar e incentivar o uso de estudos longitudinais sobre a moralidade.

Palavras-chave: Psicologia do Desenvolvimento; Moralidade; Estudos longitudinais; Adolescentes; Revisão sistemática

\begin{abstract}
The objective of this study was to systematically review the literature for checking how the longitudinal method has been applied in studies of moral development of adolescents. Searches were conducted in PsycINFO and Periodicos Capes databases, using terms like morality, adolescent and moral development. 6,229 articles were identified, of which 13 were selected based on inclusion and exclusion criteria. All articles were published between the years 2008 and 2015. The studies presented various theoretical perspectives, covering topics such as identity formation, socialization, empathy, religious commitment, and moral judgment. Also, it was identified that the studies analyzed a large number of variables operationalized. It was observed that the studies had short duration, using two or three steps, with a small interval between them. All studies effected advanced statistical analyzes. It was concluded that there is a need to improve and encourage the use of longitudinal studies on morality.
\end{abstract}

Keywords: Developmental Psychology; Morality; Longitudinal Studies; Adolescents; Systematic Review

\title{
Resumen
}

El objetivo de este estudio fue realizar una revisión sistemática de la literatura para verificar cómo se ha aplicado el método longitudinal en los estudios sobre el desarrollo moral de los adolescentes. Las búsquedas se realizaron en las bases de datos de PsycINFO y Capes Periodical, utilizando términos como moralidad, adolescencia y desarrollo moral. Identificamos 6.229 artículos, 13 de los cuales fueron seleccionados considerando criterios de inclusión y exclusión. Todos los artículos fueron publicados entre 2008 y 2015. Los estudios presentaron diversas perspectivas teóricas, abordando temas como la formación de identidad, socialización, empatía, compromiso religioso y juicio moral. Aún así, se identificó que los estudios analizaron una gran cantidad de variables operacionalizadas. Se observó que los estudios tuvieron una corta duración, utilizando dos o tres mediciones, con un pequeño intervalo de tiempo entre ellas. Todos los estudios realizaron análisis estadísticos avanzados. Se concluyó que existe la necesidad de mejorar y fomentar el uso de estudios longitudinales sobre moralidade.

Palabras clave: Psicología del desarrollo; Moralidad; Estudios longitudinales; Adolescentes Revisión sistemática

\section{Introdução}

O desenvolvimento humano é uma área de interesse da psicologia há muitas décadas. Numa publicação em homenagem ao centenário dos estudos em psicologia do desenvolvimento, Parke, Ornstein, Rieser e Zahn-Waxler (1994) organizaram uma obra que reúne as principais teorias desenvolvimentistas, que permanecem sendo utilizadas nos estudos atuais, e que são importantes para compreender os processos de 
desenvolvimento. $\mathrm{Na}$ obra, os autores apresentam desde teorias clássicas, como os pressupostos de Darwin, Binet, Freud, Piaget, Watson, Vygotsky, Werner, Bowlby, Bandura, até as perspectivas contemporâneas que surgiram a partir desses trabalhos clássicos, como a teoria do apego, os modelos de aprendizagem social, socialização parental, modelos cognitivos, neurociências.

Além da perspectiva teórica utilizada nos estudos, o uso da metodologia de coleta e análise de dados também é importante para a compreensão dos fenômenos em desenvolvimento. Nesse sentido, é possível realizar estudos sobre desenvolvimento através de métodos transversais ou longitudinais. O primeiro tipo de delineamento é o mais utilizado em todas as áreas de estudo da psicologia, devido a facilidade de coletar dados de amostras de diferentes grupos de idade ao mesmo tempo, permitindo uma comparação mais rápida e abrangente sobre a relação entre determinadas variáveis. No entanto, é importante salientar que, especificamente para analisar questões de desenvolvimento do indivíduo, tal método não é indicado como o mais eficiente, já que desconsidera as diferenças individuais e contextuais do período de desenvolvimento de cada grupo de idade (Cozby, 2003, Shaughnessy, Zechmeister e Zechmeister, 2012). Nesses casos, o delineamento mais aconselhável é o longitudinal. Nesse tipo de estudo, os mesmos participantes são analisados durante um certo período de tempo, de modo que se pode observar como determinadas variáveis se desenvolvem em cada etapa da vida. De acordo com Shaughnessy et al. (2012), nos estudos longitudinais, é possível determinar a direção e o nível de mudança em cada participante, o que permite a investigação das possíveis causas nas variáveis medidas. Apesar de tais vantagens, o método longitudinal é pouco utilizado em estudos de psicologia do desenvolvimento, devido aos custos e a dificuldade em manter contato com os participantes ao longo do tempo.

Uma das áreas em que o método longitudinal teve importância fundamental foi nos estudos da moralidade, que se dedicam a construir modelos que expliquem os processos de adoção de valores e regras morais dos indivíduos, da infância até a vida adulta. A literatura indica a fase da adolescência como uma das mais importantes, sendo um período de mudanças intensas, tanto nos aspectos cognitivos quanto sociais, marcado por definições nos conceitos morais dos indivíduos. Nesse sentido, merecem destaque os 
trabalhos de Kohlberg (1984), que utilizou do delineamento longitudinal para analisar o desenvolvimento do julgamento moral em adolescentes, elaborando uma teoria que foi a precursora nos estudos sobre a moralidade.

Kohlberg (1984) começou seus estudos sobre a moralidade através de uma investigação longitudinal, acompanhando o desenvolvimento moral de adolescentes, buscando analisar a existência de padrões de pensamento moral com o avanço da idade. Participaram deste estudo 96 adolescentes, divididos em grupos de 10, 13 e 16 anos de idade, na primeira avaliação, que responderam aos instrumentos a cada quatro anos por um período de 21 anos (seis avaliações). Os resultados deste estudo levaram a formulação de um modelo teórico, composto de seis estágios de desenvolvimento do julgamento moral, que evoluem com o avanço da idade. A comparação do pensamento moral dos mesmos indivíduos na passagem da adolescência para a vida adulta permitiu identificar que o avanço nos estágios ocorre de maneira invariante e universal, levando a perspectivas cada vez mais complexas conforme se alcançam os estágios mais elevados.

O modelo de Kohlberg foi corroborado com a realização de estudos longitudinais em outras culturas. Turiel, Edwards e Kohlberg (1978) realizaram um estudo na Turquia com 74 adolescentes com 10 anos de idade, na avaliação inicial, e 28 anos de idade, na avaliação final. Os participantes responderam a quatro medidas, com intervalos de dois, quatro e seis anos entre elas. Os resultados da comparação entre as avaliações confirmaram a sequência universal e invariante do modelo de Kohlberg. Em Israel, Snarey, Reimer e Kohlberg, (estudo descrito em Kohlberg, 1984) entrevistaram 92 adolescentes, que tinham 12 anos de idade na avaliação inicial, e responderam a três medidas, com intervalos de dois e cinco anos entre elas, tendo 26 anos na última avaliação. Os resultados confirmaram a universalidade e a sequência do modelo de estágios kohlberguiano. Assim, os resultados desses estudos mostram a impotância do uso de métodos longitudinais para compreender o desenvolvimento do indíviduo e, considerando tal importância, o presente estudo objetivou verificar, por meio de uma revisão sistemática da literatura, como este método tem sido aplicado atualmente em estudos sobre o desenvolvimento moral de adolescentes. 


\section{Método}

Foi realizada uma revisão sistemática da literatura, durante a primeira semana do mês de junho de 2015. Os artigos foram selecionados nas bases de dados PsycINFO e no portal Periódicos Capes, utilizando-se as palavras-chave moral development e longitudinal studies (utilizando o operador booleano AND) moral psychology e longitudinal studies (utilizando o operador booleano AND) e moral development e longitudinal design (utilizando o operador booleano AND). Além disso, foram considerados apenas os artigos revisados por pares, publicados nos últimos sete anos (de 2008 a 2015).

\section{Critérios de inclusão}

Após a inserção das palavras-chave e da lista de artigos encontrados, foram utilizados os seguintes termos como critérios de inclusão:

- Na busca realizada no PsycINFO: longitudinal study (na seção de métodos), e adolescents (na faixa etária da amostra do estudo).

- Na busca realizada no portal Periódicos Capes: morality, longitudinal, moral development, longitudinal studies, adolescence, adolescents.

Ainda, na busca no portal da Capes, foram utilizados os termos interviews, child development, children, parent-child relations como critérios de exclusão.

\section{Resultados}

Inicialmente, a busca utilizando as palavras-chave identificou um total de 6.229 artigos. Foram removidos 48 artigos duplicados e, após o refinamento com os critérios de inclusão e exclusão, restaram 26 artigos pré-selecionados. Uma avaliação através do conteúdo dos resumos levou a eliminação de cinco artigos, devido a inadequação dos mesmos aos objetivos deste estudo, como o fato de não serem estudos realizados com adolescentes ou não investigarem o desenvolvimento moral, por exemplo, restando 13 artigos para serem analisados.

Para atender aos objetivos deste estudo, os artigos foram analisados considerando os seguintes elementos: perspectiva teórica e revisão de estudos empíricos, variáveis 
estudadas, caracterização da amostra, quantidade de medidas e intervalos entre as medidas, e análises estatísticas realizadas para as comparações.

A Tabela 1 apresenta a perspectiva teórica e as variáveis estudadas em cada artigo. Pode-se observar que, em cinco trabalhos, os autores não apresentam o referencial teórico que orienta seus estudos. Os outros seis trabalhos apresentaram como referencial teorias sobre a formação da identidade e da personalidade, socialização, empatia, valores e, especialmente, a teoria do Julgamento Moral de Kohlberg. No que se refere às variáveis estudadas, todos os trabalhos operacionalizaram os estudos com um grande número de variáveis: cada estudo apresentou em média quatro a cinco variáveis, com destaque para o estudo de Meyhew et al. (2010), que indicaram dez variáveis a serem analisadas.

\section{Tabela 1.}

Perspectivas teóricas e variáveis estudadas pelos artigos selecionados*.

\begin{tabular}{|c|c|c|}
\hline Referência & $\begin{array}{c}\text { Referencial teórico e revisão de } \\
\text { estudos }\end{array}$ & Variáveis estudadas \\
\hline $\begin{array}{l}\text { Impet, Sorsoli, } \\
\text { Schooler, } \\
\text { Henson e } \\
\text { Tolman (2008) }\end{array}$ & $\begin{array}{l}\text { Não define referencial teórico, cita } \\
\text { algumas referências sobre a } \\
\text { perspectiva do desenvolvimento } \\
\text { feminino, como Erikson e Gilligan. }\end{array}$ & $\begin{array}{l}\text { Autenticidade da relação } \\
\text { Autoestima } \\
\text { Raça } \\
\text { Status Socioeconômico } \\
\text { Religiosidade } \\
\text { Desempenho educacional } \\
\text { Início da puberdade } \\
\text { Satisfação corporal }\end{array}$ \\
\hline $\begin{array}{l}\text { Dumas, } \\
\text { Lawford, Tieu e } \\
\text { Pratt (2009) }\end{array}$ & $\begin{array}{l}\text { Perspectiva do desenvolvimento da } \\
\text { identidade de McAdams (1993), } \\
\text { baseada na teoria de Erikson. } \\
\text { Considera o papel das narrativas no } \\
\text { desenvolvimento a partir da } \\
\text { concepção de Habermas e Bluck } \\
\text { (2000). }\end{array}$ & $\begin{array}{l}\text { Medidas de Percepção } \\
\text { Parental: } \\
\text { - estilo autoritativo } \\
\text { - coesão familiar } \\
\text { - interação parental } \\
\text { - relação positiva } \\
\text { Medidas de ajustamento } \\
\text { emocional: } \\
\text { - orientação de vida } \\
\text { - depressão } \\
\text { - felicidade } \\
\text { Medidas de Identidade } \\
\text { Códigos narrativos: } \\
\text { - resolução positiva } \\
\text { coerente } \\
\text { - severidade do evento }\end{array}$ \\
\hline
\end{tabular}


Continuação Tabela 1.

\begin{tabular}{|c|c|c|}
\hline $\begin{array}{l}\text { Velden, } \\
\text { Brugman, Boom } \\
\text { e Koops (2010) }\end{array}$ & $\begin{array}{l}\text { Teoria do Julgamento Moral de } \\
\text { Kohlberg, considerando a revisão de } \\
\text { Gibbs (2003). Apresenta o conceito de } \\
\text { atmosfera moral de Kohlberg e o de } \\
\text { Barriga, Gibbs, Potter e Liau (2001) } \\
\text { de comportamento antissocial. }\end{array}$ & $\begin{array}{l}\text { Distorções cognitvivas } \\
\text { Auto-serviço } \\
\text { Julgamento moral } \\
\text { Percepção de comunidade } \\
\text { Comportamento antissocial }\end{array}$ \\
\hline $\begin{array}{l}\text { Mayhew, Seifert } \\
\text { e Pascarella } \\
(2010)\end{array}$ & $\begin{array}{l}\text { Teoria do Julgamento Moral de } \\
\text { Kohlberg e sobre as concepções deste } \\
\text { autor sobre a construção da atmosfera } \\
\text { moral. Revisão de estudos sobre as } \\
\text { variáveis relacionadas ao raciocínio } \\
\text { moral. }\end{array}$ & $\begin{array}{l}\text { Gênero } \\
\text { Raça } \\
\text { Orientação política } \\
\text { Habilidade verbal } \\
\text { Motivação cognitiva } \\
\text { Participação em atividades } \\
\text { extracurriculares } \\
\text { Interação social } \\
\text { Comportamentos } \\
\text { relacionados ao curso } \\
\text { Qualidade das interações } \\
\text { com o professor } \\
\text { Grau de desafios acadêmicos }\end{array}$ \\
\hline $\begin{array}{l}\text { Zelli, Mallia e } \\
\text { Lucidi (2010) }\end{array}$ & $\begin{array}{l}\text { Não indica referencial teórico, } \\
\text { apresenta apenas resultados de estudos } \\
\text { anteriores sobre as variáveis. }\end{array}$ & $\begin{array}{l}\text { Variáveis } \\
\text { sociodemográficas } \\
\text { Crenças sobre o uso de } \\
\text { substâncias } \\
\text { Avaliações interpessoais } \\
\text { Uso de suplementos e } \\
\text { substâncias energéticas }\end{array}$ \\
\hline $\begin{array}{l}\text { Carlo, Mestre, } \\
\text { Sampes, Tur e } \\
\text { Armenta (2010) }\end{array}$ & $\begin{array}{l}\text { Teoria da socialização (Bandura, } \\
\text { 1986; Baumrind, 1991, etc). } \\
\text { Teorias sociocognitivas da empatia de } \\
\text { Eisemberg (1986) e Hoffman (2000). }\end{array}$ & $\begin{array}{l}\text { Estilos parentais } \\
\text { Simpatia } \\
\text { Raciocínio moral pró-social } \\
\text { Comportamentos pró- } \\
\text { sociais }\end{array}$ \\
\hline $\begin{array}{l}\text { Liljeberg, } \\
\text { Eklund, Fritz e } \\
\text { Klinteberg } \\
(2011)\end{array}$ & $\begin{array}{l}\text { Não indica referencial teórico, cita } \\
\text { estudos sobre as relações entre a } \\
\text { escolaridade e características do } \\
\text { desenvolvimento, especificamente a } \\
\text { delinquência. }\end{array}$ & $\begin{array}{l}\text { Comportamento delinquente } \\
\text { Relação escolar: } \\
\text { - compromisso escolar } \\
\text { - apego escolar } \\
\text { - apego do professor } \\
\text { - confiança do professor }\end{array}$ \\
\hline Zaff et al. (2011) & $\begin{array}{l}\text { Estudos sobre o desenvolvimento do } \\
\text { engajamento cívico em adolescentes. } \\
\text { Indica os estudos realizados a partir da } \\
\text { Perspectiva do Desenvolvimento } \\
\text { Positivo da Juventude. }\end{array}$ & $\begin{array}{l}\text { Dever cívico } \\
\text { Eficácia cívica } \\
\text { Conexão social de vizinhos } \\
\text { Participação cívica } \\
\text { Informações demográficas } \\
\end{array}$ \\
\hline
\end{tabular}




\section{Continuação Tabela 1.}

\begin{tabular}{|c|c|c|}
\hline $\begin{array}{l}\text { Padilla-Walker, } \\
\text { Fraser e Harper } \\
(2012)\end{array}$ & $\begin{array}{l}\text { Teoria da auto-determinação sobre a } \\
\text { internalização dos valores (Deci \& } \\
\text { Ryan, 2000). } \\
\text { Relação de estudos que mostram } \\
\text { variáveis relacionadas aos valores na } \\
\text { adolescência. } \\
\text { Pesquisas sobre parentalidade } \\
\text { proativa. }\end{array}$ & $\begin{array}{l}\text { Parentalidade proativa } \\
\text { Internalização de valores } \\
\text { Delinquência } \\
\text { Comportamento pró-social } \\
\text { Engajamento escolar } \\
\text { Associação desviante com } \\
\text { pares }\end{array}$ \\
\hline Lee et al. (2012) & $\begin{array}{l}\text { Não apresenta referencial teórico, } \\
\text { justifica o estudo a partir de resultados } \\
\text { de levantamentos anteriores. }\end{array}$ & $\begin{array}{l}\text { Maltrato infantil } \\
\text { Sintomas depressivos } \\
\text { Hábito de beber severamente } \\
\text { Violência } \\
\text { Fatores sociodemográficos }\end{array}$ \\
\hline $\begin{array}{l}\text { Huuskes, } \\
\text { Ciarrochi e } \\
\text { Heaven (2013) }\end{array}$ & $\begin{array}{l}\text { Não apresenta referencial teórico, se } \\
\text { baseia em estudos que abordam a } \\
\text { relação da personalidade com a } \\
\text { religião. Utilizou o modelo dos cinco } \\
\text { fatores de personalidade e o modelo } \\
\text { do Psicoticismo de Eysenchian. }\end{array}$ & $\begin{array}{l}\text { Valores religiosos } \\
\text { Cinco fatores } \\
\text { personalidade } \\
\text { Psicoticismo }\end{array}$ \\
\hline $\begin{array}{l}\text { Schnitker, Felke, } \\
\text { Barret \& } \\
\text { Emmons (2014) }\end{array}$ & $\begin{array}{l}\text { Teoria de Starbuck (1901) sobre } \\
\text { conversão e comprometimento } \\
\text { religioso, e revisão de estudos que } \\
\text { adotam essa perspectiva teórica. }\end{array}$ & $\begin{array}{l}\text { Transformação espiritual e } \\
\text { religiosa } \\
\text { Religiosidade } \\
\text { Espiritualidade } \\
\text { Comprometimento religioso } \\
\text { Funcionamento epistêmico, } \\
\text { intrapsíquico e sensibilidade } \\
\text { moral } \\
\text { Gratidão } \\
\text { Atitude e performance } \\
\text { responsável }\end{array}$ \\
\hline $\begin{array}{l}\text { Caprara et al. } \\
\text { (2014) }\end{array}$ & $\begin{array}{l}\text { Teorias sobre comportamento } \\
\text { agressivo, com foco na abordagem de } \\
\text { Bandura }(1991,1999) .\end{array}$ & $\begin{array}{l}\text { Irritabilidade } \\
\text { Ruminação hostil } \\
\text { Desengajamento moral } \\
\text { Engajamento em agressão e } \\
\text { violência }\end{array}$ \\
\hline $\begin{array}{l}\text { Krettenauer, } \\
\text { Colasante, } \\
\text { Buchmann \& } \\
\text { Malte (2014) }\end{array}$ & $\begin{array}{l}\text { Teorias sobre emoções morais em } \\
\text { crianças e adolescentes, interessados } \\
\text { nas emoções antecipadas. }\end{array}$ & $\begin{array}{l}\text { Emoções morais: mudanças } \\
\text { normativas com a idade e } \\
\text { mudanças não-normativas } \\
\text { Tomada de decisão }\end{array}$ \\
\hline
\end{tabular}

*Pesquisa realizada em junho de 2015.

A Tabela 2 apresenta as informações sobre a amostra, a quantidade e o intervalo entre as medidas longitudinais, e as análises estatísticas realizadas. Dois estudos, ao caracterizarem a sua amostra, não indicam a idade exata dos participantes nas medidas, 
apenas mencionam que os participantes eram adolescentes. Os demais estudos apresentaram amostras onde as idades variaram entre 13 e 17 anos, com destaque para o estudo de Dumas et al. (2009), que realizou a segunda medida quando os participantes estavam com 26 anos de idade, e o estudo de Lee et al. (2012), que realizou a segunda medida quando os participantes estavam com 25 anos de idade. Esses dois estudos são os que utilizaram os maiores intervalos de tempo entre as duas medidas longitudinais, nove e 14 anos, respectivamente. Ainda sobre o intervalo entre as medidas, destaca-se que, em três estudos, o intervalo entre as medidas foi de menos de seis meses. No que se refere à quantidade de medidas, sete estudos realizaram duas medidas para comparação longitudinal, enquanto os outros quatro realizaram três medidas de avaliação. Pode-se perceber, ainda, que os estudos apresentaram análises estatísticas semelhantes, predominando as estatísticas univariadas e multivariadas, com uso frequente da modelagem de equações estruturais. Destacam-se os estudos de Impet et al. (2008), que realizaram a Modelagem de Curva de Crescimento Latente (LGM), de Lee et al. (2012), que analisaram os dados a partir do pacote Multiple Imputation by Clained Equation (MICE), e de Krettenauer et al. (2014), que utilizaram a Modelagem linear Hierárquica (HLM) para verificar seu modelo.

\section{Tabela 2.}

Participantes, medidas e análises realizadas nos estudos selecionados*

\begin{tabular}{l|l|l|l}
\hline \multicolumn{1}{c|}{ Referência } & \multicolumn{1}{|c|}{ Participantes } & $\begin{array}{l}\text { Quantidade e } \\
\text { intervalo entre } \\
\text { as medidas }\end{array}$ & $\begin{array}{l}\text { Análises estatísticas } \\
\text { realizadas }\end{array}$ \\
\hline $\begin{array}{l}\text { Impet, Sorsoli, } \\
\text { Schooler, Henson } \\
\text { e Tolman (2008) }\end{array}$ & $\begin{array}{l}\text { Adolescentes do sexo } \\
\text { feminino: 170 contatadas, } \\
158 \text { respostas e 99 que } \\
\text { responderam a todas as } \\
\text { medidas. Não indica a } \\
\text { idade. }\end{array}$ & $\begin{array}{l}\text { medidas com 2 } \\
\text { por medida. }\end{array}$ & $\begin{array}{l}\text { Modelagem de curva de } \\
\text { crescimento latente } \\
\text { (LGM) }\end{array}$ \\
\hline $\begin{array}{l}\text { Dumas, Lawford, } \\
\text { Tieu e Pratt } \\
(2009)\end{array}$ & $\begin{array}{l}\text { Adolescentes de 17 anos } \\
\text { que participaram do estudo } \\
\text { até os 26 anos. 100 } \\
\text { participantes responderam a } \\
\text { todas as medidas. }\end{array}$ & & \\
&
\end{tabular}


Continuação Tabela 2.

\begin{tabular}{|c|c|c|c|}
\hline $\begin{array}{l}\text { Velden, } \\
\text { Brugman, Boom } \\
\text { e Koops (2010) }\end{array}$ & $\begin{array}{l}724 \text { estudantes de oito } \\
\text { escolas preparatórias } \\
\text { vocacionais, com idades } \\
\text { entre } 13 \text { e } 17 \text { anos. } 581 \\
\text { responderam a todas as } \\
\text { medidas. A maioria dos } \\
\text { participantes pertencia a } \\
\text { grupos minoritários. }\end{array}$ & $\begin{array}{l}2 \text { medidas com } 4 \\
\text { meses de } \\
\text { intervalo. }\end{array}$ & $\begin{array}{l}\text { Estatísticas descritivas } \\
\text { Modelagem } \\
\text { equações estruturais } \\
\text { longitudinais }\end{array}$ \\
\hline $\begin{array}{l}\text { Mayhew, Seifert } \\
\text { e Pascarella } \\
(2010)\end{array}$ & $\begin{array}{l}\text { Dados retirados de um } \\
\text { banco de dados do Instituto } \\
\text { Nabash de Estudos } \\
\text { Nacionais de Educação e } \\
\text { Artes Liberais. Foram } \\
\text { utilizados dados de } 19 \\
\text { instituições.3081 } \\
\text { participantes responderam } \\
\text { todas as medidas. Não } \\
\text { informa a idade. }\end{array}$ & $\begin{array}{l}2 \text { medidas com } 6 \\
\text { meses de } \\
\text { intervalo. }\end{array}$ & $\begin{array}{l}\text { Análises exploratórias e } \\
\text { descritivas } \\
\text { Modelos de regressão }\end{array}$ \\
\hline $\begin{array}{l}\text { Zelli, Mallia e } \\
\text { Lucidi (2010) }\end{array}$ & $\begin{array}{l}1022 \text { estudantes de } 10 \\
\text { escolas italianas, com média } \\
\text { de } 16 \text { anos de idade } \\
(\mathrm{DP}=1,5) .864 \text { responderam } \\
\text { a todas as medidas. }\end{array}$ & $\begin{array}{l}2 \text { medidas com } 5 \\
\text { meses de } \\
\text { intervalo. }\end{array}$ & $\begin{array}{l}\text { ANOVAs } \\
\text { Modelagem de } \\
\text { equações estruturais }\end{array}$ \\
\hline $\begin{array}{l}\text { Carlo, Mestre, } \\
\text { Sampes, Tur e } \\
\text { Armenta }(2010)\end{array}$ & $\begin{array}{l}988 \text { adolescentes foram } \\
\text { recrutados, } \\
\text { completaram as três } \\
\text { medidas. Média de idade de } \\
11 \text { anos. }\end{array}$ & $\begin{array}{l}3 \text { medidas com } 1 \\
\text { ano de intervalo } \\
\text { por medida. }\end{array}$ & $\begin{array}{l}\text { ANOVA } \\
\text { Modelagem de } \\
\text { equações estruturais } \\
\text { Modelagem de } \\
\text { equações estruturais } \\
\text { longitudinais }\end{array}$ \\
\hline $\begin{array}{l}\text { Liljeberg, } \\
\text { Eklund, Fritz e } \\
\text { Klinteberg }(2011)\end{array}$ & $\begin{array}{l}\text { Adolescentes de } 14 \text { anos } \\
\text { que responderam a primeira } \\
\text { medida em } 1998 \text { e } \\
\text { novamente } 18 \text { meses após. } \\
\text { O estudo contou com } 788 \\
\text { adolescentes } \\
\text { responderam às duas } \\
\text { medidas. }\end{array}$ & $\begin{array}{l}2 \text { medidas com } 1 \\
\text { ano e meio de } \\
\text { intervalo. }\end{array}$ & $\begin{array}{lr}\text { Análise } & \text { fatorial } \\
\text { exploratória } & \mathrm{e} \\
\text { confirmatória } & \mathrm{de} \\
\text { multigrupos } & \\
\text { Testes } t & \\
\text { Correlações } & \\
\text { Análises de padrão } & \end{array}$ \\
\hline
\end{tabular}


Continuação Tabela 2.

\begin{tabular}{|c|c|c|c|}
\hline Zaff et al. (2011) & $\begin{array}{l}\text { Amostra faz parte de um } \\
\text { estudo extenso sobre o } \\
\text { Desenvolvimento Positivo } \\
\text { da Juventude, com jovens } \\
\text { americanos, iniciando com } \\
\text { aproximadamente 10-11 } \\
\text { anos até } 16-17 \text { anos. O } \\
\text { estudo contou com a } \\
\text { amostra a partir dos } 13-14 \\
\text { anos. 1554 jovens } \\
\text { participaram de duas ou três } \\
\text { medidas. }\end{array}$ & $\begin{array}{l}3 \text { medidas com } 1 \\
\text { ano de intervalo } \\
\text { por medida. }\end{array}$ & $\begin{array}{l}\text { Modelagem Linear } \\
\text { Hierárquica }\end{array}$ \\
\hline $\begin{array}{l}\text { Padilla-Walker, } \\
\text { Fraser e Harper } \\
(2012)\end{array}$ & $\begin{array}{l}\text { A amostra foi retirada de um } \\
\text { Projeto de Estudos } \\
\text { Familiares. Participaram } \\
335 \text { díades familiares com } \\
\text { um adolescente entre as } \\
\text { idades de } 11 \text { e } 14 \text { anos, } \\
\text { analisados novamente dois } \\
\text { anos depois. }\end{array}$ & $\begin{array}{l}3 \text { medidas } \\
\text { um } 1 \text { com } \\
\text { intervalo de } \\
\text { medida. }\end{array}$ & $\begin{array}{l}\text { Correlações } \\
\text { Testes } t \\
\text { Análise Cluster } \\
\text { Análise de Estrutura dos } \\
\text { Momentos (AMOS) } \\
\text { Quiquadrado }\end{array}$ \\
\hline Lee et al. (2012) & $\begin{array}{l}\text { Duas coortes, retiradas de } \\
\text { um estudo longitudinal } \\
\text { contínuo. A primeira coleta } \\
\text { foi realizada em } 1987-1988 \text {, } \\
\text { com meninos de } 6-7 \text { anos e } \\
12-13 \text { anos de idade, que } \\
\text { foram acompanhados } \\
\text { durante } 14 \text { anos, até que o } \\
\text { grupo mais novo tivesse } \\
\text { com } 20 \text { anos e o mais velho } \\
\text { com } 25 \text { anos. Na segunda } \\
\text { avaliação, responderam às } \\
\text { medidas, } 849 \text { participantes. }\end{array}$ & 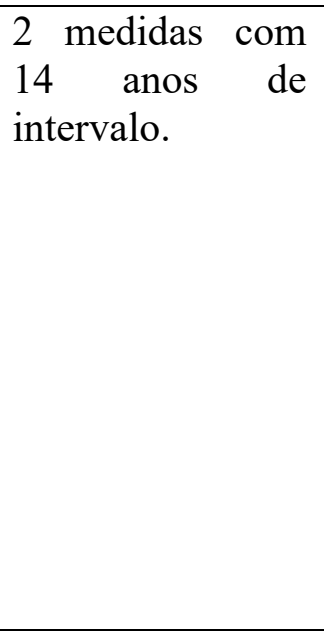 & $\begin{array}{l}\text { Análises bivariadas } \\
\text { Quiquadrado } \\
\text { Modelos de regressão } \\
\text { Análises a partir do } \\
\text { pacote Multiple } \\
\text { imputation by clained } \\
\text { equation (MICE) }\end{array}$ \\
\hline $\begin{array}{l}\text { Huuskes, } \\
\text { Ciarrochi } \\
\text { Heaven (2013) }\end{array}$ & $\begin{array}{l}765 \text { estudantes, com média } \\
\text { de } 15 \text { anos de idade } \\
(\mathrm{DP}=0,52) \text {, alunos de cinco } \\
\text { escolas católicas } \\
\text { Austrália. Destes, } 410 \\
\text { responderam a todas as } \\
\text { medidas. }\end{array}$ & $\begin{array}{l}2 \text { medidas com } 2 \\
\text { anos de intervalo. }\end{array}$ & $\begin{array}{l}\text { ANOVA } \\
\text { Correlações } \\
\text { Testes } t \\
\text { Quiquadrado } \\
\text { Modelagem de } \\
\text { equações estruturais }\end{array}$ \\
\hline
\end{tabular}


Continuação Tabela 2.

\begin{tabular}{|c|c|c|c|}
\hline $\begin{array}{l}\text { Schnitker, Felke, } \\
\text { Barret } \\
\text { Emmons (2014) }\end{array}$ & $\begin{array}{l}137 \text { adolescentes, com idade } \\
\text { média de } 16 \text { anos na } \\
\text { primeira medida. Apenas } 45 \\
\text { responderam todas as } \\
\text { medidas. }\end{array}$ & $\begin{array}{l}3 \text { medidas, tendo } \\
\text { duas semanas de } \\
\text { intervalo entre a } \\
\text { primeira e a } \\
\text { segunda e um ano } \\
\text { de intervalo entre } \\
\text { a segunda e a } \\
\text { terceira } \\
\text { avaliação. }\end{array}$ & $\begin{array}{l}\text { Estatísticas descritivas } \\
\text { para análise de } \\
\text { tendências longitudinais } \\
\text { Matriz de correlação } \\
\text { Regressão linear } \\
\text { hierárquica }\end{array}$ \\
\hline $\begin{array}{l}\text { Caprara et al. } \\
(2014)\end{array}$ & $\begin{array}{l}341 \text { adolescentes romanos, } \\
\text { com idades entre } 16 \text { e } 18 \\
\text { anos na primeira medida. } \\
\text { Não informa quantos } \\
\text { responderam a todas as } \\
\text { medidas. }\end{array}$ & $\begin{array}{l}4 \text { medidas, tendo } \\
\text { dois anos de } \\
\text { intervalo entre as } \\
\text { três primeiras } \\
\text { medidas, e quatro } \\
\text { anos de intervalo } \\
\text { entre a terceira e } \\
\text { a quarta } \\
\text { avaliação. }\end{array}$ & $\begin{array}{l}\text { ANOVA } \\
\text { Correlações bivariadas } \\
\text { entre as variáveis } \\
\text { Análise Fatorial } \\
\text { Exploratória } \\
\text { Modelagem de } \\
\text { equações estruturais }\end{array}$ \\
\hline $\begin{array}{l}\text { Krettenauer, } \\
\text { Colasante, } \\
\text { Buchmann } \\
\text { Malte (2014) }\end{array}$ & $\begin{array}{l}1258 \text { adolescentes com } \\
\text { idade média de } 15 \text { anos na } \\
\text { primeira medida. } 794 \\
\text { responderam todas as } \\
\text { medidas. }\end{array}$ & $\begin{array}{l}3 \text { medidas, com } \\
\text { intervalos de dois } \\
\text { anos entre cada } \\
\text { avaliação. }\end{array}$ & $\begin{array}{l}\text { Análises descritivas de } \\
\text { comparação entre as } \\
\text { medidas } \\
\text { Modelagem linear } \\
\text { hierárquica (HLM) }\end{array}$ \\
\hline
\end{tabular}

*Pesquisa realizada em junho de 2015.

\section{Discussão}

Considerando que os estudos longitudinais têm diminuído de frequência em psicologia, o fato de terem sido identificados 13 estudos empíricos desenvolvidos nos últimos oito anos pode ser considerado um resultado positivo. As análises das características desses estudos permitem apontar algumas questões.

No que se refere às perspectivas teóricas dos estudos identificados, considera-se que os temas levantados nos artigos são de extrema relevância para a compreensão do desenvolvimento moral de adolescentes, como a formação da personalidade, do julgamento moral e dos valores, e importância da empatia, da socialização e da religião. Porém, deve-se destacar o fato de que cinco artigos não indicaram nenhum tipo de referencial teórico, justificando seus estudos apenas a partir de resultados anteriores, o que dificulta a compreensão do leitor sobre a formulação das hipóteses e dos objetivos. Como indicado anteriormente, apontar o referencial teórico é essencial, pois um mesmo 
tema pode ser analisado de maneiras diferentes dependendo de qual perspectiva teórica adotada.

As variáveis operacionalizadas nos estudos são consideradas suficientes para atender aos objetivos. Considera-se positivo o fato de os estudos estarem considerando variáveis afetivas (depressão, sentimento de dever cívico, felicidade, autoestima), cognitivas (raciocínio moral, orientação política, distorções cognitivas) e comportamentais (participação cívica, delinquência, uso de drogas, engajamento religioso, interações sociais e comportamentos pró e antissociais) em suas análises, permitindo uma compreensão mais abrangente do desenvolvimento moral.

Sobre as amostras utilizadas, destaca-se o fato de dois estudos não indicarem a idade de seus participantes, apenas apresentarem a amostra como sendo de adolescentes. A ausência dessa informação dificulta a discussão dos resultados e impede a replicação do estudo por outros pesquisadores. Outro ponto a ser destacado é a abrangência da faixa etária dos estudos. A maioria dos trabalhos analisou adolescentes entre 13 e 17 anos, o que representa quase todo o período da adolescência, permitindo uma boa compreensão da moralidade nessa fase do desenvolvimento. No entanto, apesar da escolha da faixa etária apropriada, a maioria dos estudos utilizou duas medidas de comparação longitudinal, com intervalos de apenas alguns meses entre essas medidas. Considerando que o objetivo de qualquer estudo longitudinal é realizar uma comparação do desenvolvimento do indivíduo ao longo de um período de tempo, realizar uma comparação com poucas medidas e pouco tempo de intervalo entre elas impede uma análise aprofundada de um determinado fenômeno em desenvolvimento.

Outro aspecto positivo dos estudos revisados é o uso de técnicas estatísticas avançadas para analisar os resultados das comparações longitudinais, como a modelagem de equações estruturais e de curva de crescimento latente, análises AMOS e pelo pacote MICE. Essas técnicas permitem comparações específicas entre as variáveis e fornecem muitas informações úteis, especialmente para fazer inferências sobre o desenvolvimento das variáveis ao longo do tempo.

Para concluir, é necessário fazer um apontamento sobre os resultados dos estudos. Apesar de não ser um dos aspectos considerados neste estudo para a análise das características dos estudos longitudinais em desenvolvimento moral, é importante dizer 
que todos os estudos revisados apresentaram resultados relevantes para a compreensão da relação entre variáveis do desenvolvimento moral, sendo úteis para esta área de estudo, e servindo de referência para estudos futuros. Deve-se indicar, apenas, que os resultados foram apresentados de maneira muito resumida em alguns artigos, o que dificulta a replicação e comparação destes com estudos futuros. É recomendado que os estudos apresentem detalhadamente todos os resultados relevantes para a compreensão dos fenômenos.

\section{Considerações finais}

Os resultados deste estudo de revisão foram esclarecedores sobre o panorama dos estudos longitudinais em psicologia do desenvolvimento moral, e suscitam alguns pontos que devem ser considerados para estudos futuros nessa área. Primeiramente, verifica-se a necessidade de um maior rigor na descrição metodológica dos estudos. Essas informações precisam ser explicitadas com clareza, para permitir a replicação dos estudos, um princípio básico para a construção do conhecimento científico. Além disso, um aspecto mais grave foi identificado: o tempo de duração dos estudos. Como foi indicado na fundamentação teórica deste artigo, os estudos clássicos sobre $o$ desenvolvimento moral tiveram duração de mais de dez anos, e os autores acompanharam a evolução dos participantes até o início da fase adulta. Os estudos realizados nos últimos anos diminuíram esse intervalo para poucos anos, e até meses de duração. O que caracteriza um estudo longitudinal não é somente o fato de haver mais de uma medida do mesmo participante, mas que seja realizado um acompanhamento ao longo de um certo tempo para verificar o desenvolvimento de alguma característica, o que não pode ser realizado adequadamente num estudo que acompanha uma pessoa durante alguns meses. Recomenda-se que se amplie o intervalo entre as medidas e a duração dos estudos futuros.

É preciso destacar, ainda, a necessidade da realização de estudos brasileiros dessa natureza. Não foi identificada, no presente estudo, nenhuma publicação nacional de estudos longitudinais voltados para o desenvolvimento moral. De maneira geral, é necessário incentivar o uso das análises longitudinais, não só para a compreensão dos 
processos de desenvolvimento moral como em outros aspectos do desenvolvimento humano, considerando as vantagens que esse tipo de comparação proporciona.

\section{Referências}

Caprara, G.V., Tisak, M.S., Alessandri, G., Fontaine, R.G., Fida, R, \& Paciello, M. (2014). The Contribution of Moral Disengagement in Mediating Individual Tendencies Toward Aggression and Violence. Developmental Psychology, 50, 71-85. doi: $10.1037 / \mathrm{a} 0034488$.

Carlo, G., Mestre, M.V., Samper, P., Tur, A., \& Armenta, B.E. (2011). The longitudinal relations among dimensions of parenting styles, sympathy, prosocial moral reasoning, and prosocial behaviors. International Journal of Behavioral Development, 35, 116124. doi: $10.1177 / 0165025410375921$

Cozby, P. C. (2003). Métodos de pesquisa em ciências do comportamento. São Paulo: Atlas.

Dumas, T.M., Lawford, H., Tieu, T., \& Pratt, M.W. (2009). Positive Parenting in Adolescence and Its Relation to Low Point Narration and Identity Status in emerging Adulthood: A Longitudinal Analysis. Developmental Psychology, 45, 1531-1544. doi: 10.1037/a0017360

Huuskes, L., Ciarrochi, J., \& Heaven, P.C.L. (2013). The longitudinal relationships between adolescent religious values and personality. Journal of Research in Personality,47, 483-487. doi: 10.1016/j.jrp.2013.04.010

Impett, E.A., Sorsoli, 1., Schooler, D., Henson, J.M., \& Tolman, D.L. (2008). Girls' Relationship Authenticity and Self-esteem Across Adolescence. Developmental Psychology, 44, 722-733. doi: 10.1037/0012-1649.44.3.722

Kohlberg, L. (1984). Essays on Moral Development. The Psychology of Moral Development: The Nature and Validity of Moral Stages. Vol. 2. San Francisco: Harper \& Row.

Krettenauer, T., Colasante, T., buchman, M., \& Malti, T. (2014). The development of Moral Emotions and Decision Making From Adolescence to Adulthood: A 6-Year Longitudinal Study. Journal of Youth Adolescence, 43, 583-596. doi: 10.1007/s10964013-9994-5

Lee, C., Cronley, C., White, H.R., Mun, E., Stouthamer-Loeber, \& Loeber, R. (2012). Racial Differences in the Consequences of Childhood Maltreatment for Adolescent and Young Adult Depression, Heavy Drinking, and Violence. Journal of Adolescent Health, 50, 443-449. doi: 10.1016/j.jadohealth.2011.09.014 
Liljeberg, J.F., Eklund, J.M., Fritz, M.V., \& Klinteberg, B. (2011). Poor school bonding and delinquency over time: Bidirecional effects and sex differences. Journal of Adolescence, 34, 1-9. doi: 10.1016/j.adolescence.2010.03.008

Mayhew, M.J., Seifert, T.A., \& Pascarella, E.T. (2010). A Multi-Institutional Assessment of Moral Reasoning Development among First-Year Students. The Review of Higher Education, 33, 357-390. doi: 10.1353/rhe.0.0153

Padila-Walker, L.M., Fraser, A.M., \& Harper, J.M. (2012). Walking the walk: The moderating role of proactive parenting on adolescents' value-congruent behaviors. Journal of Adolescence, 35, 1141-1152. doi: 10.1016/j.adolescence.2012.03.003

Parke, R.D., Ornstein, P.A., Rieser, J.J., \& Zahn-Waxler, C. (Eds.) (1994). A Century of developmental psychology. Wasington, DC: American Psychological Association.

Schnitker, S.A., Felke, T.J., Barrett, J.L., \& Emmons, R.A. (2014). Longitudinal Study of Religious and Spiritual Transformation in Adolescents Attending Young Life Summer Camp: Assessing the Epistemic, Intrapsychic, and Moral Sociability Functions of Conversion. Psychology of Religion and Spitiruality, 6, 83-93. doi: $10.1037 / \mathrm{a} 0035359$

Shaughnessy, J.J., Zechmeister, E.B., \& Zechmeister, J.S. (2012). Metodologia de Pesquisa em Psicologia. Porto Alegre: AMGH.

Turiel, E., Edwards, C.P., \& Kohlberg, L. (1978). Moral Development in Turkish Children, Adolescents and Young Adults. Journal of Cross-Cultural Psychology, 9, 75-85.

Van der Velden, F., Brugman, D., Boom, J., \& Koops, W. (2010). Moral cognitive processes explaining antisocial behavior in young adolescents. International Journal os Behavioral Development, 34, 292-301. doi: 10.1177/0165025409343705

Zaff, J.F., Kawashima-Ginsberg, K., lin, E.S., Lamb, M., Balsamo, A., \& Lerner, R.M. (2011). Developmental trajectories of civic engagement across adolescence: Disaggregation of an integrated construct. Journal of Adolescence, 34, 1207-1220. doi: 10.1016/j.adolescence.2011.07.005

Zelli, A., Mallia, L., \& Lucidi, F. (2010). The contribution of interpersonal appraisals to a social-cognitive analysis of adolescents' doping use. Psychology of Sport and Exercise, 11, 304-311. doi: 10.1016/j.psychsport.2010.02.008 